\title{
Towards a demand forecast methodology for recurrent disasters
}

\author{
J. Vargas Florez ${ }^{1,3}$, M. Lauras ${ }^{1}$, L. Dupont ${ }^{1}$ \& A. Charles ${ }^{2}$ \\ ${ }^{1}$ Université de Toulouse, Mines Albi, France \\ ${ }^{2}$ Université Lumière Lyon 2, France \\ ${ }^{3}$ Department of Engineering, the Pontifical University Catholic of Peru, \\ Peru
}

\begin{abstract}
Humanitarian supply chains have received a lot of attention over the last fifteen years, and can now be considered a new research area. But a gap exists between the research work proposals and their applications in the field. One of the main issues is that the demand, in the case of disaster, is hard to assess because of the high-level of uncertainty. Gathering knowledge about future demand is of prime importance to be able to propose models, which are relevant to implement for a real problem. This paper tackles this problematic proposing a four-step methodology for forecast disaster impact, and in this way, the future demand, such as cyclones in the Caribbean or earthquakes along the Pacific Ring of Fire. This approach uses data analysis techniques such as Principal Component Analysis and Multivariate Regression Analysis. An application case on Peruvian earthquake demand is proposed to illustrate the benefits of our approach.
\end{abstract}

Keywords: forecast, disaster, demand, principal component analysis, multivariate regression analysis.

\section{Introduction}

Almost every year, losses due to natural disasters are increasing. For instance, the damages from natural disasters in 2011 (US\$366 billion and more than 260 million people impacted) reached a level never seen before, with annual average damages for the 2000-2011, around US\$100 billion (EM-DAT [1]). In the meantime, the funding of humanitarian operations has been multiplied by thirteen (www.reliefweb.int) over the last decade. All these facts have pushed 
humanitarian organizations to become more result-oriented. They need to prove to donors that the funds they get are used in the most efficient way. But because of what is at stake, that is to say human lives, they also need to ensure that, whatever the circumstances, those who need their help are rescued quickly and effectively.

Consequently, Humanitarian Supply Chains (HSC) received a lot of attention over the last fifteen years, and can now be considered a new research area. The number of scientific and applicative publications has considerably increased over this period and particularly over the last five years. Reviews in humanitarian logistics and disaster operation management allowed bringing out trends and future research directions dedicated to this area (Altay and Green [2]; Van Wassenhove [3]; Natarajarathinam et al. [4]; Charles et al. [5]; Peres et al. [6]). These authors show that the HSC research projects are mainly based on the development of analytical models followed by case studies and theory. As for research methodologies, mathematical programming is the most frequently used method. But few or no humanitarian organizations go as far as using optimization-based decision-support systems.

This demonstrates that a real gap exists between the research work proposals and their application on the field. To bridge this gap authors proposed some trails among which: (i) Humanitarians naturally evolve in a very hazardous environment and the academic works must consider the uncertainties they face more systematically. For instance, a broad majority of the research works is deterministic and only a few of them propose stochastic approaches; (ii) A consequence of the previous points is that the research work should be more realistic, considering real problems and real data gathering past and future trends (Van Wassenhove [3]; Charles et al. [5]). Due to the youth of this academic area, researchers find it difficult to get accurate, and above all, reliable data to support their steps towards improvement (Van Wassenhove [3]; Peres et al. [6]); (iii) Future research works should consider the new requirement on efficiency for humanitarian organizations. Productivity and efficiency studies are challenging issues that have gained importance to humanitarian operations because of the donor's pressure on humanitarian organizations to deliver aid to beneficiaries in a cost-effective way (Kovács and Spens [7]).

Furthermore, one of the main issues is forecast disasters' demand. In case of humanitarian crisis, this point is particularly hard to reach regarding the highlevel of uncertainty. But without any attempt on that point, too many academic propositions are still purely theoretical. Gathering knowledge about future demand is the prime importance to be able to propose models, which are relevant to implement for a real problem.

This paper tackles this issue by proposing a demand forecast methodology dedicated to the disaster management context. The paper is split up in four parts. The first section will present a brief literature review on demand in humanitarian context. The second section will describe the proposed method and its associated tools. The third section will develop an application case on Peruvian earthquakes' demand. The last section will discuss the limits of the approach and propose some perspectives on this research. 


\section{Background}

In the case of humanitarian organizations, uncertainty reaches a climax. "Natural disaster risk assessment is a typical issue with imprecision, uncertainty and partial truth. The two basic forms of uncertainty related to natural disaster risk assessment are randomness caused by inherent stochastic variability and fuzziness due to macroscopic grade and incomplete knowledge sample" taken from Huang and Shi [8]. The usual methods to deal with uncertainty are to use a stochastic or a robust optimization model. Both need at least some knowledge about the future demand. Stochastic optimization uses probabilities of occurrence whilst robust optimization uses various alternatives, from the most optimists to the worst case scenarios. Stochastic optimization models optimize the random outcome on average. According to Shapiro et al. [9], "this is justified when the Law of Large Numbers can be invoked and we are interested in the long-term performance, irrespective of the fluctuations of specific outcome realizations". In our case, the impact of those "fluctuations" plays on human lives and can be devastating. As for robust location problems, according to Snyder in [10], they proved difficult to solve for realistic instances. If a broad majority of the published research works is deterministic, more and more humanitarian researchers now propose stochastic models in order to better consider uncertainty (Martel et al. [11]). But stochastic or not, the problem is that since most natural disasters are difficult to foresee, the demand for goods in these disasters also is difficult to manage (Cassidy [12]; Murray [13]). And, even when a crisis occurs, the environment changes so quickly that most of the time information is either not available or not reliable. However, humanitarians could benefit a lot from better visibility on future needs corresponding to future disasters, even it is rough.

Generally, humanitarian practitioners have to make their decision with or without information on the magnitude of the disaster. Disasters are generally characterized by a high-level of uncertainty on both their occurrence and impacts are not easily anticipating (Vitoriano et al. [14]). Nevertheless, those on past disasters' information are well known. The EM-DAT database for instance contains essential core data on the occurrence and effects of over 18,000 mass disasters in the world from 1900 to present. The question is how to exploit this information in order to give some visibility to decision-makers and practitioners. Whether the problem concerns occurrence and impact forecasts, the literature review shows that the occurrence dimensions is globally tracked. A lot of work and tools regarding natural disaster prediction (flood, volcano eruption, earthquake, storms so on) have already been developed. Earthquake prediction models for instance try specifying the time, location, and magnitude of a future earthquake with precision (WGCEP [15]). Moreover according to the current thinking, disaster trends are changing. If we refer to EM-DAT [1]; Charles et al. [5]; IFRC [16]; IPCC [17], disasters should be more numerous, but of smaller or medium scale in the future. Added to this is the urbanization, which further alters the impact of disasters. The studies of the potential impact of climate change also predict developments in the types of disaster recorded their locations, and their 
intensities. In practice, analyses of the data from past disasters allow providing valuable information regarding the trends of disasters (localization, intensity, typology and seasonality, so on). The results of Charles et al. [5] about African casualties, show that occurrences are not so randomly, they share characteristics such as seasonality, location and targeted-population, so future humanitarian occurrences, though highly uncertain, can be predicted. Other researchers such as Peres et al. [6] or Kovács and Spens [7] consider that for small and medium size disasters, future occurrence will be globally similar to previous ones. Regarding this kind of disaster, in Charles [18] for instance has identified by studying the EM-DAT database on a ten-year period that the occurrence and intensity of disasters were globally constant during the decade. But if the occurrence of disasters seems to be managed following this approach, the question of their consequences (number of victims and associated needs) must be examined.

Actually, the impact dimension seems for now not to be really studied in the literature. Disaster impact is defined by UNISDR [19] as, "the potential disaster losses, in lives, health status, livelihoods, assets and services, which could occur to a particular community or a society over some specified future time". In Wisner et al. [20] demonstrate in their research that the disaster impact is function of the vulnerability of the concerned area. Vulnerability factor was defined by UNDP [21], as "the characteristics and circumstances of a community, system or asset that make it susceptible to the damaging effects of a hazard". While the vulnerability factor is fundamental to explain disaster impact, it cannot be considered sufficient. Many other research works studied in survey proposed by Peres et al. [6] or Vitoriano et al. [14] insist on the importance of the resilience capability to explain the impact that follows a disaster. Many acceptations can be found in the literature regarding the resilience concept, but it can be defined as the "capacity to resist and to recover after exposition of a system, community or society, to hazards" Peres et al. [6]. Inspired on UNESCAP [22] synthesizes the previous information by indicating that disaster impact is a function of both; resilience and vulnerability.

$$
\text { Disaster Impact }=f(\text { Vulnerability, } \text { Resilience })
$$

\section{Proposition}

Our approach concerns the particular case of recurrent disasters such as storms in Caribbean, foods in South-East of Asia or earthquakes in the Andes.

In this research, we made the assumption that the disaster occurrence forecasts are similar to the previous recorded disasters. Consequently, disaster demand forecast will depend only on the future disaster impact assessment. Based on these hypotheses, we propose the following approach to assess future disasters' demand (see Figure 1):

The first step consists of identifying the influencing factors that allow qualifying the vulnerability and resilience level of a potential impacted area. A thorough literature review was done by UNDP [21]; D'Ercole et al. [23]; D'Ercole and Metzger [24]; Alinovi et al. [25] allows us identifying 58 generic 


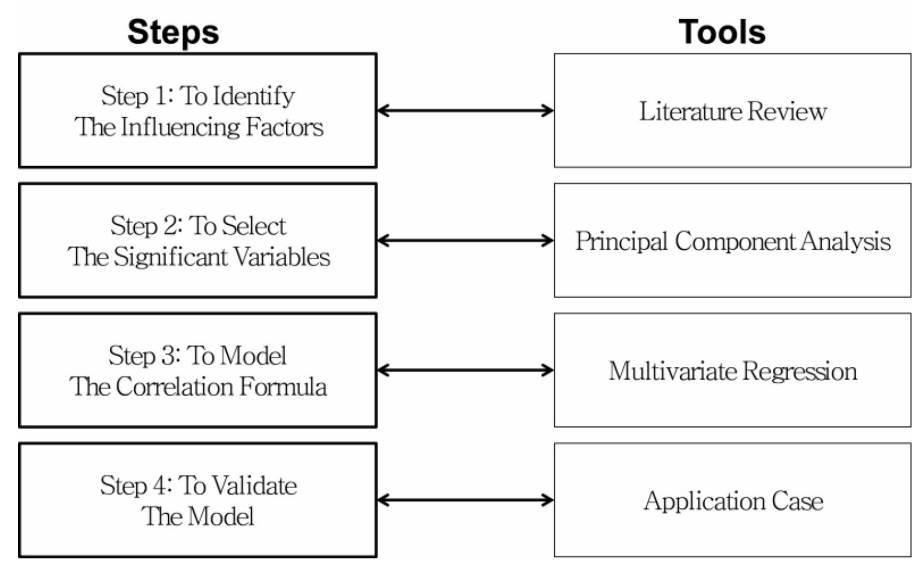

Figure 1: Disaster demand forecast methodology.

factors to characterize the vulnerability and the resilience of the potential impacted area. These include demographics, economic, environmental, health and accessibility indicators. Tables 1 and 2 show this list of indicators. We could remark that all these indicators cannot be applied to all kinds of natural disasters. Some of them are only representative for earthquakes, floods or volcano eruptions for instance.

The second step consists of selecting a subset of significant independent variables among influencing factors identified in Step one. To support this step, we propose to use Principal Component Analysis (ACP) inspired in Saporta [26] and Vargas-Florez et al. [27], in order to identify the discriminating variables

Table 1: $\quad$ Generic influencing factors for Vulnerability.

Income and Food Access: Average per person daily income (local currency/person/day); Average per person daily expenditure (local currency / person/day); Household food insecurity access score; Dietary diversity and food frequency score, Dietary energy consumption (Kcal/person/day).

Access to Basic Services: Physical access to health services; Quality score of health services; Quality of educational system; Perception of security; Mobility and transport constraints; Water, electricity and phone networks.

Social Safety Nets: Amount of cash and in-kind assistance (local currency/person/day); Quality evaluation of assistance; Job assistance; Frequency of assistance (number of times assistance received last 6 months); Overall opinion of targeting.

Assets: Housing (number of rooms owned); Housing equipment index (TV, Car, etc.); Tropical livestock unit (TLU) equivalent to $25 \mathrm{~K}$; Land owned (in hectares).

Adaptive Capacity: Diversity of incomes sources; Educational level (household average); Employment ratio (ratio, number of employed divided by household size); Available coping strategies; Food consumption ratio (by expenditure).

Stability: Number of household members that have lost their job; Income change; Expenditure change; Capacity to maintain stability in the future; Net safety dependency (share of transfers on the total income); Education system stability, the Human de Development Index (IDH). 
Table 2: $\quad$ Generic influencing factors for Resilience.

\begin{tabular}{l} 
Exposure of resources: Zoning by seismic exposition, also inundation zones due to tsunami \\
hazards. \\
\hline Access to resources: Accessibility of resources in emergency situation. \\
\hline Functional and vulnerability structures: Structural vulnerability; major bridges, \\
interchanges; Structural function \& vulnerability key health facilities. \\
\hline Access to resources and vulnerability of the population: Access to resources (rate resource / \\
population); Population by age; Population by access to services; Population without access to \\
any services; Average population by households by room; Population without potable water; \\
Population without drainage system; Population without electricity; Households with average \\
people per room; Population living with dirt floors; Population settlements resulting from \\
land's invasion; \% Population that are newcomers to the district; \% Population with low \\
education; Accessibility due to urban design; Exposure to Hazards. \\
Vulnerability humanitarian response: Governance humanitarian response system; Quality of \\
system, processes, services and tasks; Maturity and expertise humanitarian institutions; \\
Decision and intervention centers available; Water supply hubs available; Food supply \\
available; Health care available; Energy supply available; Transport, roads and accessibility \\
available; Telecommunications available; Shelters area available; Waste dumps disposable \\
areas available; Economic and finance support; Keep permanent measure system population \\
vulnerability updated; Keep measure system hazard seismic updated; Keep measure system \\
tsunami threat updated; Keep a database robustness and updated base
\end{tabular}

associated to a given type of disaster. The objective consists of reducing the size of the problem and finding the discriminating variables that will be used in the linear regression in Step three.

The third step consists of modelling the correlation formula that allows assessing the future demand, using a multivariate regression analysis. Actually, for a given disaster's occurrence (earthquake with a magnitude of seven for instance), two different areas would not record the same impact due to their own vulnerability and resilience capabilities. Considering the previous frame we define for each impacted localization at past, the following association:

$$
\text { Past Disaster Impact }=f\left(V_{1}, V_{2}, \ldots, V_{m} ; R_{1}, R_{2}, \ldots, R_{n}\right)
$$

in which:

$\left\{V_{l}, \ldots, V_{m}\right\}$ are the vulnerability discriminating variables identified during the PCA analysis. $\left\{R_{l}, \ldots, R_{n}\right\}$ are the resilience discriminating variables identified during the PCA analysis.

Based on these equations, we estimate, for a potential impacted localization and for a given period of time $t$, an expected gravity using a multivariate regression model. In words of Sopipan et al. [28], if explanatory independent variables have multicollinearity the forecasting calculation can be defined as:

$$
\text { Future Disaster impact }=f_{t=1, \ldots, T}\left(X_{1}, \ldots, X_{k}, \ldots, X_{m x n}\right)
$$

in which:

$X_{k}$ is independent variable composed of $\{m \times n\}$ values recorded in a given period $t$, from a database which carry a total $T$ periods. 
The fourth step consists of verifying and validating the relevance of the proposed regression models. To support this step, we propose to make a comparative analysis, in order to measure the deviation between the forecast calculated by the model and the real needs that have been recorded on the field, it defines as Ratio. A deviation ratio criterion is proposed:

If $75 \%<$ Ratio $<100 \%$ then the model is considered as "good"; If $50 \%<$ Ratio $<75 \%$ then the model is considered as "doubtful"; If Ratio $<50 \%$ then the model is considered as "bad".

\section{Application case}

In this section, we present a numerical application case in order to illustrate the benefits of our contribution regarding the management of earthquake disasters in Peru. Analysis of historical data on Peruvian earthquakes shows clearly that the small and medium size earthquakes' occurrences are globally recurrent in frequency and intensity (Castillo and Alva [29]).

\section{Step 1:}

It has made a pre-selection of 12 influencing factors among those 58 generic proposed, relate to vulnerability and resilience influence on earthquake case. The following table shows these:

Table 3: Vulnerability and resilience factors for earthquake disasters.

\begin{tabular}{|c|c|c|c|c|c|c|}
\hline \multirow{2}{*}{ Vulnerability } & Population & IDH & Water ${ }^{1}$ & Electricity & $\begin{array}{c}\text { Vulnerable } \\
\text { walls }{ }^{2}\end{array}$ & $\begin{array}{c}\text { Life expectancy } \\
\text { birth }\end{array}$ \\
\cline { 2 - 7 } & quantity (millon) & ratio & $\%$ & $\%$ & $\%$ & years \\
\hline \multirow{3}{*}{ Resilience } & Illiteracy & $\begin{array}{c}\text { Secondary } \\
\text { registration }\end{array}$ & $\begin{array}{c}\text { Educative } \\
\text { achievement }\end{array}$ & $\begin{array}{c}\text { Family per } \\
\text { cápita income }\end{array}$ & $\begin{array}{c}\text { Criminal } \\
\text { records }\end{array}$ & $\begin{array}{c}\text { Support } \\
\text { logistics }\end{array}$ \\
\cline { 2 - 7 } & $\%$ & $\%$ & $\%$ & S/. mes & quantity (mil) & (S/. millon ) \\
\hline
\end{tabular}

${ }^{1}$ Continuous supply services: public network within the housing.

${ }^{2}$ It is considering those houses whose walls are of adobe, thatch or mud.

For each of the 24 Peruvian regions, the values of these 12 factors regarding three representative years (1993, 2000 and 2007) have been gathered from public governmental, NGOs and International organizations databases such as: National Institute of Statistics and Informatics (INEI), Peruvian Ministry of Education (MINEDU) and so on.

\section{Step 2:}

Following our methodology, we implemented an ACP on whole vulnerability and resilience data, for instance see Table 4 about resilience. We have to notice that the ACP has gotten $88.69 \%$ of data variance. The results can be considered meaningful and can be interpreted. This data analysis allowed identifying correlations between the 12 influencing factors that we retained. For instance the Human Development Index (HDI) is so correlated with life expectancy, 
Table 4: Resilience data for 1993, 2000 and 2007 for the 24 Peruvian regions.

\begin{tabular}{|c|c|c|c|c|c|c|c|c|c|c|c|c|c|c|c|c|c|c|}
\hline \multirow[t]{2}{*}{ Region } & \multicolumn{3}{|c|}{ Illiteracy } & \multicolumn{3}{|c|}{$\begin{array}{l}\text { Secondary } \\
\text { registration }\end{array}$} & \multicolumn{3}{|c|}{$\begin{array}{c}\text { Educative } \\
\text { achievement }\end{array}$} & \multicolumn{3}{|c|}{$\begin{array}{l}\text { Family per cápita } \\
\text { income }\end{array}$} & \multicolumn{3}{|c|}{ Criminal records } & \multicolumn{3}{|c|}{ Support logistics } \\
\hline & 1993 & 2000 & 2007 & 1993 & 2000 & 2007 & \begin{tabular}{|l|l|}
1993 \\
\end{tabular} & 2000 & 2007 & 1993 & 2000 & 2007 & 1993 & 2000 & 2007 & 1993 & 2000 & 2007 \\
\hline Amazonas & 79,5 & 82,9 & 88,0 & 40,8 & 51,5 & 78,6 & 66,6 & 72,4 & 84,9 & 65,8 & 195,37 & 204,7 & 5,23 & 6,40 & 0,81 & 0,0 & 1,6 & 0,3 \\
\hline Ancash & 78,1 & 80,8 & 87,6 & 65,1 & 75,1 & 86,3 & \begin{tabular}{|l|}
73,8 \\
\end{tabular} & 78,9 & 87,2 & 87,9 & 307,27 & 320,8 & 7,88 & 8,20 & 4,50 & 0,0 & 0,0 & 0,4 \\
\hline Apurímac & 63,0 & 70,4 & 78,3 & 43,9 & 63,7 & 89,9 & 56,6 & 68,2 & 82,2 & 52,0 & 137,49 & 203,3 & 1,63 & 1,56 & 1,13 & 0,0 & 0,0 & 2,3 \\
\hline Arequipa & 92,0 & 93,6 & 95,9 & 82,7 & 92,4 & 90,7 & \begin{tabular}{|l|l}
88,9 \\
\end{tabular} & 93,2 & 94,2 & 149,9 & 331,33 & 434,8 & 16,32 & \begin{tabular}{|l|l|}
11,07 \\
\end{tabular} & 9,19 & 0,0 & 1,6 & 1,6 \\
\hline Ayacucho & 67,2 & 71,7 & 71,7 & 46,9 & 69,8 & 69,8 & \begin{tabular}{|l|}
60,4 \\
\end{tabular} & 71,1 & 71,1 & 62,9 & 167,91 & 167,9 & 2,26 & \begin{tabular}{l|l}
3,90 \\
\end{tabular} & 2,19 & 0,0 & 0,0 & 0,0 \\
\hline Cajamarca & 72,7 & 77,8 & 82,9 & 41,3 & 51,6 & 79,6 & \begin{tabular}{|l|}
62,2 \\
\end{tabular} & 69,1 & 81,8 & 62,9 & 198,44 & 215,7 & 2,25 & 3,89 & 2,29 & 0,0 & 0,0 & 2,9 \\
\hline Cusco & 73,8 & 83,3 & 86,1 & 54,5 & \begin{tabular}{|l|l}
65,4 \\
\end{tabular} & 87,6 & \begin{tabular}{|l|}
67,3 \\
\end{tabular} & 77,3 & \begin{tabular}{|l|}
86,6 \\
\end{tabular} & \begin{tabular}{|l|}
98,6 \\
\end{tabular} & 259,75 & 262,5 & 11,57 & 4,62 & 4,07 & 0,0 & 2,1 & 2,3 \\
\hline Huancavelica & 65,7 & 72,5 & 79,9 & 45,9 & 61,2 & 86,7 & \begin{tabular}{|l|l|}
59,1 \\
\end{tabular} & 68,7 & 82,2 & 42,0 & 142,06 & 131,9 & 0,75 & 2,00 & 0,02 & 0,0 & 0,0 & 0,0 \\
\hline Huánuco & 75,0 & 77,4 & 83,4 & 41,4 & 55,4 & 81,7 & \begin{tabular}{|l|}
63,8 \\
\end{tabular} & 70,1 & 82,8 & \begin{tabular}{|l|}
60,5 \\
\end{tabular} & 191,82 & 231,6 & 3,85 & 4,08 & 0,99 & 0,0 & 0,0 & 0,3 \\
\hline Ica & 94,2 & 95,7 & 97,2 & 87,8 & 93,4 & 89,7 & 92,0 & 94,9 & 94,7 & 125,2 & 357,79 & 371,9 & 7,48 & |5,77 & 2,55 & 0,0 & 0,0 & 13,0 \\
\hline Junín & 86,3 & 88,1 & 92,4 & 70,2 & 85,8 & 86,2 & \begin{tabular}{|l|l|}
80,9 \\
\end{tabular} & 87,3 & 90,4 & 91,4 & 253,06 & 278,1 & 11,86 & 2,87 & 1,71 & 0,0 & 0,0 & 2,7 \\
\hline La Libertad & 86,2 & 89,0 & 91,9 & 66,0 & 71,8 & 82,0 & \begin{tabular}{|l|}
79,5 \\
\end{tabular} & 83,3 & 88,6 & 101,3 & 338,24 & 381,3 & 14,81 & \begin{tabular}{|l|l}
10,78 \\
\end{tabular} & 9,76 & 0,0 & 0,0 & 0,3 \\
\hline Lambayeque & 88,7 & 89,5 & 93,5 & 70,7 & 75,1 & 85,3 & \begin{tabular}{|l|}
82,7 \\
\end{tabular} & 84,7 & 90,8 & 103,2 & 343,20 & 318,4 & 9,86 & 9,95 & 8,47 & 0,0 & 0,0 & 0,6 \\
\hline Lima - Callao & 87,1 & 96,2 & 98,2 & 77,7 & \begin{tabular}{|l|l|}
94,6 \\
\end{tabular} & 89,2 & \begin{tabular}{|l|}
84,0 \\
\end{tabular} & 95,7 & \begin{tabular}{|l|}
95,2 \\
\end{tabular} & 189,7 & 547,47 & 552,1 & \begin{tabular}{|l|}
145,90 \\
\end{tabular} & \begin{tabular}{|l|l}
19,90 \\
\end{tabular} & 67,83 & 0,0 & 4,5 & 2,9 \\
\hline Loreto & 88,8 & 92,0 & 94,5 & 47,3 & 60,5 & \begin{tabular}{|l|}
79,2 \\
\end{tabular} & \begin{tabular}{|l|}
75,0 \\
\end{tabular} & 81,5 & \begin{tabular}{|l|l|}
89,4 \\
\end{tabular} & 99,4 & $265,28 \mid$ & 279,1 & 6,36 & 2,90 & 3,49 & 0,0 & 1,8 & 0,7 \\
\hline Madre de Dios & 92,0 & 92,7 & 96,8 & 61,5 & \begin{tabular}{|l|l|}
85,7 \\
\end{tabular} & 83,3 & \begin{tabular}{|l|}
81,8 \\
\end{tabular} & 90,4 & \begin{tabular}{|l|}
92,3 \\
\end{tabular} & \begin{tabular}{|l|}
127,6 \\
\end{tabular} & 327,47 & 429,8 & 1,99 & 5,95 & 1,39 & 0,0 & 0,0 & 0,2 \\
\hline Moquegua & 91,0 & 92,6 & 95,3 & 85,6 & \begin{tabular}{|l|l}
91,0 \\
\end{tabular} & 91,1 & \begin{tabular}{|l|}
89,2 \\
\end{tabular} & 92,1 & \begin{tabular}{|l|l}
93,9 \\
\end{tabular} & 121,0 & 412,72 & 418,2 & 1,85 & 5,21 & 1,44 & 0,0 & 0,0 & 0,6 \\
\hline Pasco & 84,6 & 89,1 & 91,7 & 70,5 & 89,4 & 85,0 & \begin{tabular}{|l|}
79,9 \\
\end{tabular} & 89,2 & \begin{tabular}{|l|}
89,5 \\
\end{tabular} & 81,2 & 233,75 & 222,4 & 1,12 & 4,61 & 0,33 & 0,0 & 0,0 & 0,1 \\
\hline Piura & 83,2 & 86,9 & 90,8 & 59,2 & 70,0 & 82,4 & \begin{tabular}{|l|}
75,2 \\
\end{tabular} & 81,3 & 88,0 & 100,6 & 209,18 & 313,8 & \begin{tabular}{|l|}
10,74 \\
\end{tabular} & \begin{tabular}{|l|l}
5,17 \\
\end{tabular} & 5,52 & 0,0 & 2,5 & 0,6 \\
\hline Puno & 77,6 & 79,5 & 87,8 & 65,3 & 82,4 & 86,5 & \begin{tabular}{|l|}
73,5 \\
\end{tabular} & 80,5 & \begin{tabular}{|l|}
87,3 \\
\end{tabular} & 55,5 & 179,72 & 208,8 & 7,92 & \begin{tabular}{l|l}
0,83 \\
\end{tabular} & 1,61 & 0,0 & 1,6 & 4,1 \\
\hline San Martín & 87,1 & 89,6 & 92,3 & 46,1 & 56,3 & 77,7 & 73,5 & 78,5 & 87,4 & 93,6 & 220,57 & 255,4 & 2,86 & 2,78 & 1,34 & 0,0 & 1,6 & 1,3 \\
\hline Tacna & 92,5 & 93,0 & 96,3 & 77,3 & 83,9 & 89,7 & 87,4 & 90,0 & 94,1 & 193,8 & 420,45 & 410,4 & 7,06 & 8,52 & 1,08 & 0,0 & 0,8 & 0,4 \\
\hline Tumbes & 93,3 & 93,4 & 96,6 & 73,4 & 82,5 & 85,4 & \begin{tabular}{|l|}
86,7 \\
\end{tabular} & 89,8 & \begin{tabular}{|l|}
92,9 \\
\end{tabular} & \begin{tabular}{|l|}
124,9 \\
\end{tabular} & 311,84 & 412,8 & 3,92 & \begin{tabular}{l|l}
7,29 & \\
\end{tabular} & 1,53 & 0,0 & 0,0 & 0,2 \\
\hline Ucayali & 89,9 & 90,9 & 95,2 & 54,1 & 76,5 & 80,2 & \begin{tabular}{|l|l|}
78,0 \\
\end{tabular} & 86,1 & 90,2 & 91,2 & 257,43 & 313,4 & 3,39 & \begin{tabular}{|l|l|}
6,98 & \\
\end{tabular} & 2,86 & \begin{tabular}{l|l|}
0,0 \\
\end{tabular} & 0,9 & 0,4 \\
\hline
\end{tabular}

illiteracy, secondary registration, education achievement, income per capita, water and electricity accessibility indexes, meanwhile Criminal Records (CR) is so correlated with population density index, all the cases have $\mathrm{R} \geq 0.82$. Furthermore, the three factors should be retained to explain the whole behaviour of the influencing factors regarding disaster impact $(D V)$ : (i) $X_{H D I}$ for human development index (vulnerability of society); (ii) $X_{C R}$ for criminal records (resilience of society); (iii) $X_{V W}$ for building vulnerability (vulnerability of walls).

Based on these three discriminating variables, we made a second ACP as shown on the factorial plan presented in Figure 2 (more than $90 \%$ of data variance).

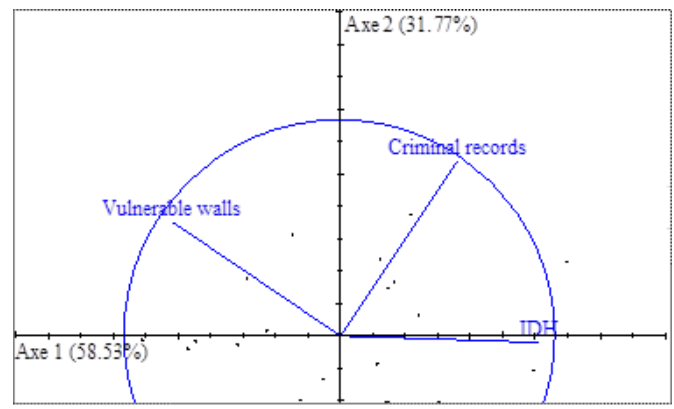

Figure 2: $\quad$ Factorial plan of principal component analysis. 
Step 3:

It consists of establishing the regression equation based on the three discriminating variables identifying in previous step that should allow assess potential volume of victims for a given period in a given region. As discussed in section 3, we used a multivariate regression analysis to reach this goal. Our numerical application was based on Peruvian earthquakes recorded in 1993, 1995, 2000 and 2007. For instance for Lima-Callao region its regression equation is:

$$
D V_{\text {Lima-Callao }}=+184733.8 \times X_{I D H}+0.468 * X_{C R}-1485837 \times X_{V W}+16908.35
$$

Based on all Peruvians regions' equations found, we could assess future disaster impacts for the year 2014 regarding attempted values for $X_{H D I}, X_{C R}$ and $X_{V W}$. Data for each Peruvian region in 2014 have been sourced through a benchmark step with Chile, which gets very similar characteristics to Peru. The results of the disaster impact forecast for the year 2014 are presented in Table 5.

The approach should be generalized for forecast disaster impacts for a longer time frame. Based on these results, we will be able to establish realistic facilitylocation model in order to support Peruvian's earthquakes prepositioning inventory strategy.

Table 5: 2014 disaster impact forecasts for the 24 Peruvian regions.

\begin{tabular}{|c|c|c|c|c|c|c|c|c|c|c|}
\hline \multirow[t]{2}{*}{ No } & \multirow[t]{2}{*}{ Regions } & \multirow[t]{2}{*}{1993} & \multirow[t]{2}{*}{1995} & \multirow[t]{2}{*}{2000} & \multirow[t]{2}{*}{2007} & \multirow{2}{*}{$\begin{array}{c}\text { Forecast } \\
2014\end{array}$} & \multicolumn{2}{|c|}{$\begin{array}{c}\text { Reliable } \\
\text { results }\end{array}$} & \multicolumn{2}{|c|}{$\begin{array}{l}\text { Seismic } \\
\text { region }\end{array}$} \\
\hline & & & & & & & Yes & No & Yes & No \\
\hline 1 & Amazonas & 3333 & 1881 & 4916 & 1161 & 4982 & 1 & & & \\
\hline 2 & Ancash & 1440 & 830 & 2406 & 491 & 3227 & 1 & & 1 & \\
\hline 3 & Apurimac & 0 & 812 & 372 & 3815 & 2037 & 1 & & & \\
\hline 4 & Arequipa & 80 & 4586 & 18022 & 1823 & -49988 & & & & 1 \\
\hline 5 & Ayacucho & 610 & $\begin{array}{ll}5 & 047 \\
\end{array}$ & 1286 & 262 & 38811 & 1 & & & \\
\hline 6 & Cajamarca & 8650 & 205 & $\begin{array}{ll}7 & 145 \\
\end{array}$ & 732 & -4867 & & 1 & & \\
\hline 7 & Cusco & 2000 & 2302 & 28 & 11697 & 46202 & 1 & & & \\
\hline 8 & Huancavelica & 95 & 1248 & 66 & 44733 & -115138 & & 1 & & \\
\hline 9 & Huanuco & 3877 & $\begin{array}{ll}4 & 187\end{array}$ & 54 & 1969 & 1007 & 1 & & & \\
\hline 10 & Ica & 0 & 6400 & 10 & $355 \quad 332$ & 416248 & 1 & & 1 & \\
\hline 11 & Junin & 632 & 1218 & 42 & 3267 & 4643 & 1 & & & \\
\hline 12 & La Libertad & 100 & 5 & 19 & 526 & -5794 & & 1 & & 1 \\
\hline 13 & Lambayeque & 0 & 0 & 11 & 101 & 61 & 1 & & & \\
\hline 14 & Lima-Callao & 3282 & 4308 & 213 & 56116 & 127738 & 1 & & 1 & \\
\hline 15 & Loreto & 392765 & 2672 & 279 & 2590 & 488711 & 1 & & & \\
\hline 16 & Madre de Dios & 215 & 1245 & 3 & 134 & 1699,5 & 1 & & & \\
\hline 17 & Moquegua & 50 & 6438 & 13 & 179 & 1467,8 & 1 & & 1 & \\
\hline 18 & Pasco & 183 & 849 & 8 & 724 & 1776,1 & 1 & & & \\
\hline 19 & Piura & 0 & 2565 & 10 & 1733 & 3819,9 & 1 & & & \\
\hline 20 & Puno & 1150 & 3007 & 30 & 5335 & 10224 & 1 & & & \\
\hline 21 & San Martin & 12787 & 2304 & 40 & 1865 & -342977 & & 1 & & \\
\hline 22 & Tacna & 2350 & 20 & 13 & 20 & $-8646,8$ & & 1 & & 1 \\
\hline 23 & Tumbes & 525 & 750 & 5 & 49 & $-804,51$ & & 1 & & \\
\hline 24 & Ucayali & 0 & 1628 & 3 & 1609 & 2225,4 & 1 & & & \\
\hline & & & & & & Total & 17 & 6 & 4 & 3 \\
\hline & & & & & & Equivalence & $74 \%$ & $26 \%$ & $57 \%$ & $43 \%$ \\
\hline
\end{tabular}




\section{Step 4:}

In this step, we verify the relevance of our approach by re-calculating the disaster impacts of the year 2014 through our regression equations. For all the regions $74 \%$ of the simulated results matched with the real number within a deviation inferior to $10 \%$. On the other hand, for regions that had been submitted to a strong earthquake (as Pisco, in 2007, Chandes and Gilles [30]), the matching rate drops down to $57 \%$ within a deviation inferior to $10 \%$.

\section{Conclusions and future work}

In this paper we have proposed a methodology able for forecast disaster impacts associated to recurrent disasters such as cyclones in Caribbean, earthquakes in Pacific ring of fire, floods in South-East Asia, so on. Our approach is based on two main assumptions. The first one considers that regarding such a disaster, future occurrences can be taken as globally equivalent to the past ones. The second one considers that future disaster impacts will depend on two main factors; vulnerability and resilience.

Based on these hypothesis, our proposal is split up into four steps: (i) Identifying the vulnerability and resilience factors through literature review; (ii) Selecting discriminating variables among these factors through Principal Component Analysis; (ii) Establishing regression equations for a given period of time and a given area, through multivariate regression analysis; (iv) Validating the relevance of the model through standard deviation analysis.

This proposition was applied to the Peruvian earthquakes situation in order to support future strategic thoughts on inventory pre-positioning.

Regarding this work, the next steps will consist in designing a facilitylocation model that can use such approach to determine the demand. This future model will try to reach a triple goal in terms of disaster management performance: (i) agility for a better responsiveness and effectiveness; (ii) efficiency for a better cost-control; (iii) robustness for a better deployment even if some infrastructures are not available any more.

\section{References}

[1] EM-DAT, www.emdat.be, 2011.

[2] Altay, N. and Green, L.V., OR MS research in disaster operations management, European Journal of Operational Research, 175(1), pp. 475493, 2005.

[3] Van Wassenhove, L.N., Humanitarian aid logistics: supply chain management in high gear, Journal of the Operational Research Society, 57, pp. 475-489, 2006.

[4] Natarajarathinam, M., Capar, I., and Arunachalam, N., Managing supply chains in times of crisis: a review of literature and insights, International Journal of Physical Distribution and Logistics Management, 39(7), pp. 535-573, 2009. 
[5] Charles, A., Lauras, M. and Van Wassenhove, L.N., A model to define and assess the agility of supply chains: building on humanitarian experience, International Journal of Physical Distribution and Logistics Management, 40(8/9), pp. 722-741, 2010.

[6] Peres, E.Q., Brito Jr, I., Leiras, A. and Yoshizaki, H., Humanitarian logistics and disaster relief research: trends, applications, and future research directions, Proc. of the 4th International Conference on Information Systems, Logistics and Supply Chain, pp. 26-29, 2012.

[7] Kovács, G. and Spens, K.M., Humanitarian logistics in disaster relief operations, International Journal of Physical Distribution and Logistics Management, 37(2), pp. 99-114, 2007.

[8] Huang, C. and Shi, Y., Towards efficient fuzzy information processing, Springer, 2002.

[9] Shapiro, A., Dentcheva, D. and Ruszczynski, A.P., Lectures on Stochastic Programming. BPR Publishers: Philadelphia, 2009.

[10] Snyder, L.V., Facility location under uncertainty: a review, IIE Transactions, 38(7), pp. 547, 2006.

[11] Martel A., Benmoussa A., Chouinard M., Klibi W. and Kettani O., Designing global supply networks for conflict or disaster support: the case of the Canadian Armed Forces, Journal of the Operational Research Society, 64, pp. 577-596, 2013

[12] Cassidy, W.B., A logistics lifeline, Traffic World, October 27, pp. 1, 2003.

[13] Murray, S., How to deliver on the promises: supply chain logistics, Financial Times, January 7, pp. 9, 2005.

[14] Vitoriano B., Montero J., Ruan D. (Ed.), Decision Aid Models for Disaster Management and Emergencies, 7(1), pp. 46, Springer Publishers, 2013.

[15] WGCEP, 2007 Working Group on California Earthquake Probabilities, The Uniform California Earthquake Rupture Forecast, Version 2 (UCERF 2): USGS Press, 2008.

[16] IFRC, International Federation Red Cross Red Crescent. Red Cross/Red Crescent Climate Guide, Climate Change: the Basics, Tech. rep, 2007.

[17] IPCC, Intergovernmental Panel on Climate Change, Summary for Policymakers. Climate Change 2007: Impacts, Adaptation and Vulnerability. Cambridge University Press. Cambridge, pp. 7-22, 2007.

[18] Charles A., 2010, PHD Thesis, Improving the design and management of agile supply chain: feedback and application in the context of humanitarian aid, Toulouse University, France.

[19] UNISDR, United Nations International Strategy for Disaster Reduction. 2009 UNISDR Terminology on Disaster Risk Reduction. UN Press: New York, pp. 9, 2009.

[20] Wisner B., Blaikie P., Cannon T., and Davis I., At risk. Natural people's vulnerability and disasters, pp. 7-258, Routledge: New York, 2004.

[21] UNDP, United Nations Development Programme. Reducing disaster risk: a challenge for development. A global Report. UN Press: New York, pp. 146, 2004. 
[22] UNESCAP, United Nations, Economic and Social Commission for Asia and the Pacific, Building Community Resilience to Natural Disasters through Partnership: Sharing Experience and Expertise in the Region, pp. 3, UN Press: New York, 2008.

[23] D’Ercole R., Hardy S., Metzger P., Robert J. and Gluski P., Les dimensions spatiales et territoriales de la gestion de crise à Lima, VertigO - La Revue Electronique en Sciences de l'Environnement, 12(1), 2012.

[24] D’Ercole R. and Metzger P., La vulnérabilité territoriale : une nouvelle approche des risques en milieu urbain, European Journal of Geography, 447s paper, 2009.

[25] Alinovi L., Mane E. and Romano D., Measuring Household Resilience to Food Insecurity: Application to Palestinian Household, EC-FAO Food Security Programme, FAO Press, pp. 3-10, 2009.

[26] Saporta G., Simultaneous Analysis of Qualitative and Quantitative Data, Proc. of the XXXV Riunione Scientifica della Societa Italiana di Statistica, pp. 63-72, 1990.

[27] Vargas-Florez J., Charles A., Lauras M. and Dupont L., Towards a method for qualitative and quantitative assessment of humanitarian disaster demand forecast, Proc. of 4th World conference Production and Operations Management, 2012.

[28] Sopipan N., Kanjanavajee W. and Sattayatham P. (2012), Forecasting SET50 Index with Multiple Regression based on Principal Component Analysis, Journal of Applied Finance and Banking, 2(3), pp. 271-294, 2012.

[29] Castillo L.J. and Alva E.J., Peligro Sísmico en el Perú, Proc. of the 7th Congreso Nacional de Mecánica de Suelos e Ingeniería de Cimentaciones, pp 6-10, 1993.

[30] Chandes, J. and Gilles P., To Ponder on the Collective Actions in the Context of Humanitarian Logistics: Lessons from the Earthquake in Pisco. Journal of Economics, Finance and Administrative Science, 14(28), 2009. 